\title{
Research on Competitive Sports in the Visual Field of Science and Technology Ethics---Survey on "the Nature of Human Fades away" in Competitive Sports
}

\author{
Lanfang Liu (Corresponding author) \\ Technical Philosophy, Sports Ethics, Tianjin University of Sport \\ PO box 167, South of Weijin road 51 He Xi district, Tianjin300381, China \\ E-mail: liuerlanfang@yahoo.com.cn
}

$\mathrm{Te} \mathrm{Bu}$

Sports Philosophy, Sports of Management, Tianjin University of Sport

PO box 167, South of Weijin road $51 \mathrm{He}$ Xi district, Tianjin300381, China

E-mail: buteagu@sina.com

\begin{abstract}
The Progress of Science and technology has substantially increased the development of Competitive sports. At the same time, it is changing the man in the natural balance. Based on the natural value of competitive sports, this essay makes a survey on "the nature of human fades away" in competitive sports and tries to find the mutual tolerance of binding site of competitive sports and science and technology: the use of science and technology in competitive sports should not only been limited properly but also realize the "soft landing" of science and technology ethics.
\end{abstract}

Keywords: Competitive sports, Human nature, Limit, Soft landing

During the long history of human development, the development of competitive sports demonstrates a chaotic and primeval status of natural harmony. In that case, the ethic relationship which competitive sports presented was fair and balanced in people's image. It is no doubt that scientific exploitation makes competitive sports full of vitalities. But on the other hand, the ethical issues in human science of physical culture and sports are accompanied, which leads the moral hazard of competitive sports. The change of ethic relationship emerged from technical dissimilation, the confusion of morale will definitely affect the sustainable development of competitive sport without the thinking and control on human reason.

\section{1. "The fade away of human nature" in competitive sports}

With the development of hi-tech industry, the main body of scientfic activities masters a great power. Science has already become an omnipresent element in modern society and the living environment, which has a direct influence on the survival and development of human in present and future. Sciences' technique is a double-edged sword. It makes human beings depend 100 percent on itself, which is so called "humanized nature", while it increases the productive and change the nature world "humanized". Hence, the relationship between human and materials dissimilates. At first, human was the subject in this relationship while materials were the object, this kind of relationship is to know and be known, to change and be changed. But nowadays, the relationship is reversed. Human becomes not only the object to face against the subject, but also becomes slaves of machines. It is not human to rule and manipulate machines; on the contrary, it is machines become the ruler of the human. Therefore, when the nature is marked by human, society and era, the nature of human has a relatively tendency of extinctive. To take a view from the development track of Olympic, modern technique has gradually changed its role from a "borrower" to a "supporter", then becomes a role to be relied on, and finally turns into a "independent". Which means the character of modern technique has fundamentally changed, technique is no longer a introduced stuff, it changes into an internal logic which decides the direction and speed of modern Olympic and makes Olympic turn into a "sports--technique system". The essence of competitive sports is to tap human's potential, promote human's perfection and development. But when the sports technique becomes the physical object and the competition between men evolves into the competition for technology, which is weaker contract with athletes, competitive sports become activities in science and technology, so the movement of the technical dissimilation eventually leads to the alienation of competitive sports.

The fundamental theory of Marxism holds that human is the entity of nature and sociality. The original intention 
of competitive sports requires human's comprehensive and unconstrained development. During this process, the naturalness of human plays an important role, it is not an instinct, it is generated during the interaction process between human and nature. The sociality was generated by the communication of humans. As one of the essences of human, naturalness requires confirmation through its objectives. Human needs interaction to confirm their sociality. In this case, human need to interact with nature to confirm their natural essence. Thus it can be seen that human can only confirm their natural exist instead of their animality exist through nature.

In some sense, the development of technology facilitates the invasion from human sociality to human naturalness. As the most immediate representative, human's nature body is the result of billions of years natural evaluative. The development of technology changed human's natural body a lot. Dialectically speaking, human can not oppose to the technological transformation at large, for it is no doubt that the progress of technology enhances the quality of human body. For instance, technology helps a lot on the mode of motion, training condition and cites equipment, which makes human conquer themselves and reach the maximum of sports. But meanwhile, human is exerting technology to improve their body as their self logical image to cater to the development of competitive sports. As a result, the competition of competitive sports in the present world is mainly about the competition of technology. In such a competition, on the one hand there is no personality, the subject of competitive sport becomes a dependency of technology, it turns into a "model" that according to what technology wants it to be. On the other hand, things which has a closely connection with technology, such as economy and politics boarded the stage of history. Many countries' competitive sports lose on the starting line because of the poverty of economy and the un-development of technology.

Naturalness is the premise and foundation of human sociality. Therefore, the most primary natural relationship exists in the interpersonal social relationship. This relationship is the real human relationship, the key point is not how much the technological content is, it concerns the globality of humanity system and the harmonious of mutual emotion and moral. Being different from human naturalness, human sociality was engendered during the process of the communication between human and nature; it remains the pureness of nature and the simple form between human and nature. Due to that, technology, as a tool, shouldn't intervene or shouldn't intervene too much in some field. It is evident that the tendency of "valuing equipment while devaluing people"," tooling" in modern Olympic games. Imagine that if the mainly influence of athletes are fading away in competitive games and "tools" takes over the world, the essence of competitive sports is violated.

Human naturalness will never outmode. As a effective tool, technology shouldn't make human naturalness fade away. On the contrary, it should facilitate the developing and harmonious of both human and nature. In that case, it can facilitate the integrity, peculiarity and fertility of humanity system, which reaches the competitive sports ethic principle: respecting life, enhancing health, expanding engagement, fair competition, promoting harmony.

\section{Reflection on "Regression of Man's Naturalness" in Competitive Sports}

German scholar Jaspers once depicted the mentality of modern people. According to him, contemporary men have been part of a mechanism, they "lessen, and at last lose their passion toward other people and common things, and no longer spare any time or enthusiasm on contemplating on life itself......here comes a paradox: the more man relies on this mechanism, the more likely that man will be destroyed because of the perfection or breakdown of the mechanism." Man is having more and more reliability on science and technology, while no creativity left for himself. So it's with competitive sports, as the implementation of science and technology has brought about too huge a disparity among sportsmen from different nations. Athletes from developed nations enhance their performance with the latest technologies, while the ones from developing nations have nothing to do with this. Thus the disadvantaged athletes are lagging farther and farther behind. How can we expect fairness in this case? In other words, the one that enhances and gains the achievements in sports is no longer the sole athlete himself, but the compound of the athlete and technology. In this way the body that's responsible for performances in sports is not the mere athlete, but the compound of the athlete and technology. This means, the body attribute of persons is deprived of by technology, persons no longer being the sole body. With the loss of his body attribute, man's central role in the Olympics is lost as well.

The original meaning of scientific is to bring benefit to human and help them get more freedom and liberation. Nevertheless, as the scientific itself has dehumanization, it makes scientific dissimilate. On the status of dissimilation, scientific is no longer a tool service for human, but a power to rule human and oppress their dissident power, the power deprives human freedom and makes human to be belonged. The prominent manifestation is the overflow of stimulant; it is also the biggest crisis Olympic Games faces. In 2000 Sydney and 2004 Athens Olympic Games, the positive rate of doping control raise again greatly. 11 and 26 players were examined violation. In 2008 Beijing Olympic Games the inspection was unprecedented. A series of struck, 
hommization rules were made. But in 2010 Vancouver Winter Olympic games, 30 athletes were expulsion because of stimulant. It is obviously that the anti-doping task is a heavy road to walk. "Health" and "fairness" are the focuses of competitive sports, but profits cause the ethic deliberation, when scientific is exploited as a baton, people can't help themselves to miss the ancient Olympic, the beauty and enjoyment bring from fair play are the true essence of competitive sports.

\subsection{The natural value of competitive sports.}

Generally speaking, the concept of natural value is not a new word, nor the only conception in Ecological Ethics. Although the original meaning it was put forward was to find a theoretical fulcrum to the Ecological Ethics, it was gradually extended to a rationale of the moral obligation of human protecting the environment. Hereon, we can discuss the subject "human" in competitive sports as a part of nature. The originator of Land Ethics Leopold hold that we should understand the value as a property of an object, and human can only understand the property of value through experience. He thought that the natural value is objectively exist through its property and it won't change by human will. It is objectively exist no matter people like or dislike, admit or deny. The property of natural value is objective; the evaluating ability of human is given by the nature. It is not the existence of natural value depends on human, but the evaluating is created because of natural existence.

To take a look from the phylogeny of Olympic, the generation and development are formed through the relationship between human and nature. In that case, it is no doubt that the essence of competitive sports is branded with natural value. Talking about the essence of competitive sports, Smith said: fundamentally speaking, competitive sports are the elongation of game, game is its foundation, the main value of competitive sports is derived from game. Otherwise, game is a behaviour or active which proceeded in an explicitly stipulated time and space, it is proceeded by spontaneous acceptable rules. Once the rules are accepted, they have absolute force of constraint. The purpose of the game is among the game itself, being different from daily life, it is accompanied by emotions such as nervous and pleasure. Since the technicality, organization, physical facilities and scientific applications of competitive sports have reached a certain degree, competitive sports hold in gregariousness and openness may become a activity which lost its inherent property of game. So Weiz defined competitive sports as " a series rules be proved by people who pursuit the excellence through physical activity and made them traditional. ICSPE stipulate competitive sports as "every movement contains property of game and compete with others or the natural obstacles." In their opinion, the purpose of competitive sports is to express the potential of human physique, physical ability, mentality and locomotives; technique is the method to achieve such a purpose. The principle of the competitive sports is to ensure the game fair and square. The result of the competitive sports is to objectification the essence of the athletic subject and combine self-improvement of athletic subject and the expression of essential strength.

The development process of the competitive sports reflects its value in the same way. Trace back to the development of ancient Olympic, the generation and continuous development, frame and content of the model relates tightly with the geography and the religions, fete ceremony, city-state system in Greece, its attention to education system and the ethnic character of admiring hero. In the sense of Greece society, "hero" is another name of "god" in reality. Greek dedicate to physical exercises with great passion to make their body as perfect as god, this might be the real motivation of loving sports in some sense. The intension of hero and goodness are the same in Greeks philosophical thinking, consequently to get the champion in Olympic Game is a way to be a hero. In that case, the human natural value given by competitive sports can be expressed as superhuman power, harmonious movements, spectacular speed, impeccable technique and strong muscles.

The autonomy, democracy, equality and law government praised highly by Greece city-state system is the security of human ideological emancipation and cult of personality; it is also the power base of ancient Olympic Games. Justice issue has been discussed as a focal point of exerting scientific into competitive sports. Justice contains initial justice, procedural justice and outcome justice in sport competition, outcome justice is what people pursue for. But initial justice and procedural justice are the guarantee of outcome justice. It is easy to imagine if the competition becomes a scientific competition, especially when it is covered by scientific negative effect, physical education itself would lose its value. As the features of competitive sports are totally different, many athletes don't stint to violate the rule of P.E and use stimulant drugs to challenge their maximum. It violates the fairness doctrine fundamentally and harm the purpose of Olympic: participant, competition, justice, friendship and struggle.

\subsection{To think twice before using scientific into competitive sports.}

Technology played a significantly catalytic role in the process that when human beings in the "homeless" status, similarly, with the development of science and technology, sports show a prosperous appearance. Human beings 
continually use science and technology to challenge their own limitations and moral principles. In Had egger's view, the modern technology is essentially a framework of fate, as for human, it is just a kind of given things (das Gewahrte), while for the receiver (das Gawahrende), it is a kind of giving (das Gewahren).Only the given things is continuing. The originally continuing thing is the giver." (6) Hedegger pointed out that modern technology is not only for the essence of man but also for the covering are extremely dangerous, this fate is also is a kind of totally given, and it is in the framework of the given fate," the inner destruction of the people not to give it the subordination of those exposed - if we start to think about their role according to the nature of technology the words. "(7) short, the frame fate of modern technology contains the saving force, The giver is as this kind of giver is just the saving strength that things in this or that kind of way to send to the covering.

The existence of technology has it rationality and necessity, which cannot be overthrown, and be destroyed. To adapt a new stage form, giving full play and avoid the irrational rationality, science and technology itself must undergo a new historical turning point.

Kant proposed that "man makes laws for nature ", man is a natural subject;

But Hedegger's thinking on technology can be directly interpreted that "nature makes laws for man", man belongs to nature. Now, we use technology in competitive sports just as a tool. What 're technologies can be used? And what're technologies should not be used? When is the reasonable time? And who is the suitable use will break sports ethics? Those cross-examinations finally point to the existence of natural body in competitive sports.

For a long time, as the development of science and technology, the capacity to transform and use nature has been strengthened, Scientifics in vogue, it is arrogant to think that human knowledge can achieve the "Omega point", Science and technology can change people's everything, the things destroyed can make use of more advanced technology to redeem. British scientist J. Jeans assured us: "We no longer believe that the destiny of mankind belongs to good or bad spirit or the playing conspiracy demon doll. Nothing can prevent us from constructing the earth to heaven again --- unless we hinder their own dawn of scientific age has come, we have found that human is his own master of his destiny, and the captain of his soul boat. "I.e. any difficulties faced by human beings can be created by man invented ways to solve; there is an only temporary unsolvable difficulty, not always unsolvable problems. As Proved by science: the world of science is never a complete world, human can never achieve that sacred "Omega Point"; technology has it's own limitations, it is only when we can accurately calculate things man can control things, but the accurate prediction of the technology is very limited, so the task of technology is to understand the world rather than to control the world. Therefore, in the process of applying science and technology, we must insist on the limitation that science and technology is the auxiliary principle in the application of in competitive sports. When the technology is back to auxiliary role, it is still one of the human activities, and man is the protagonist, so man's dominant position will not be shaken, and the impact of the plight of people missing the dominant position will not happen again. The determination principles in the field of technology application in the modern Olympics, are an important specification, but should adhere to the principle of appropriate application. Ethical issues in Competitive Sports are almost produced on the basis of technology: the over-reliant on technical methods to improve the level of sports abilities, in order to make body adapt to the inorganically technical requirements, which will come to the results that athletes are hurt and aggravated the injury in the unnatural movement.

\section{The "soft landing" of science and technology ethics in competitive sports}

Because of the concealment and deceptive of the competitive sports' technical dissimilation phenomena, "the fade away of human naturalness" has not been awarded. Therefore, it is necessary to eliminate the technological paradox in modern competitive sports, and make people realize the value of competitive sports again.

Actually, technology and ethics are the different forms of human society. When re-examining the competitive sports based on the Science and Technology Ethics, we will find competitive sports depart farther and farther from its purpose due to the political purpose, economic benefit and professional activities. Therefore with the rapid development of science and technology, the more intelligent way is to introduce the ethics of "soft landing" mechanism. The "soft landing" of science and technology ethics mechanism is actually the buffering mechanism between technology and ethical values which mainly includes two aspects:

\subsection{To establish the reasonable technological values of competitive sports.}

The Natural value of the competitive sports is the respect for the original life. However, application technology in sports destroys life and cause the fade away of human naturalness, which is not coherent with purpose of competitive sports and destroys the root of sports. Meanwhile, competitive sports are to develop of human being's physical, mental and psychological potentials. Not only can it sustains one's life, but also undertakes the 
obligation of the improvement. The employ of technology alienation is at the expense of the subject's physical and mental harm. Therefore, people must have the appropriate attitude on the technical rationality and technical value, have a better understanding of the negative effect of science and technology and establish a basic idea of the limitations of science and technology from the traditional view of conquering the nature. The limitation of science and technology is objective: It can change the natural material, energy and information, replace people's manual and partial mental labour, but is difficult to change people's biological nature. It can improve people's living standard, expand range of living fields, and modernizing living means, but it can not solve man's thoughts and beliefs and ethical issues. Although it can replace natural entity with technique entity, natural process with technical process, the results are not equal to natural entity and the natural process of reproduction. The reasonable technological values require people to see the usefulness of science and technology as well as the limitation of it in the process of the development of competitive sports. Technology is a complex being, so people should take an active attitude to face the negative effects of science and technology, and limit and eliminate the technology which destroys the original competitive sports consciously. However, the negative effects of science and technology become invisible, it is a dialectic negation process for people to use and limit the science and technology, at the same time as the tool rationality and value rationality of the science and technology is also in a constant changing state, therefore, people must establish the reasonable technological value in the construction of ecological technology.

\subsection{To establish the reasonable ethics evaluation system of competitive sports.}

During the development of competitive sports, we stand against the wrong values of one-sided exaggeration on science and technology, advocate technological ethics, and establish the reasonable ethics evaluation system of competitive sports. People can't simply deny that material productive forces including modern technology play the most important role in historical development of human society. However, we should realize the negative effects of science and technology when the science and technology shows its super control and we must reconstruct human value coordinate and value orientation calmly and clearly. At a theoretical and cognitive level this requires us to discard all the wrong ideas of disrupting the ecological balance of nature, intensify the publicity of sports ethics education in constructing the sustainable development of competitive sports, which is based on the Ethics of science. Firstly, the social public should have an extensive, thorough, and specific discussion about the Ethics value issues which is new or possible to appear owing to the employment of science and technology in competitive sports. Therefore, the opposition and the prudent will be presented to the public, and then through the layers of deep discussions and negotiations, people can reach a certain degree of consensus for the ethical acceptable conditions of new technology within which we can accelerate the development of science and technology. Secondly, technology worker and the decision maker of sports should reveal the potential danger of new technology to competitive sports subject as objectively, fairly and reasonably as possible, and restrict its activities by using the value criterion and the ethics spirit consciously. Thirdly, the key of establishing the reasonable ethics evaluation system of competitive sports is that athletes, coaches and sports team must have a better understanding of the sportsmanship and values promoted in competitive sports, which is an effective inner power resisting the improper use of technology.

\section{References}

Chao Mengqin. (2003). New-humanism and ecological ethics----a re-cognition about philosophical foundation of ecological ethics. Academic Research. No.2.

Deng Bin. (2005). The development tendency of the dope test of Olympic Games. Bulletin of Sport Science \& Technology. Sept 2005.

Dong Chuansheng. (2004). Dilemmas of philosophy and Dispelling to Hi-tech Olympics. Dongbei University Press.

Dong Chuansheng. (2004). Dilemmas of philosophy and Dispelling to Hi-tech Olympics. Dongbei University Press.

Heidegger. (1988). Die Technik und Die Kehre. 7 Ed. Trans. Flynn. Verkhoyansk neville's Press,1988.P.31.

Heidegger. (1988). Die Technik und Die Kehre. 7 Ed. Trans. Flynn. Verkhoyansk neville's Press, 1988. P.32.

Karl Jaspers. (1997). Man in the Modern Age [M]. Trans. Wang Defeng. Shanghai Translation Publishing House. 1997.43-53.

Schmits, K. L. (1988). Sport and play: suspension of the ordinary. In:Morgan, K. J. and Meier, K.V. (Eds.) Philosophic Inquiry in Sport.Human Kenitics: Champaign, Illinois, P. 29.

Si Kehu. Zhu Kun. Zhao Bingjun. (2006). Effect of Sport Moral Risk on Development of Competitive Sports. China Sport Science. No. 2.

Xie Xunhuan. (2005). Threat to Sustainable Development for Sports Doping. Journal of Chengdu Sport University. No. 3. 